\title{
Alimentação de fêmeas de jundiá com fontes lipídicas e sua relação com o desenvolvimento embrionário e larval
}

\author{
Use of lipid sources on feeding jundiá (Rhamdia quelen) and its relation with embryo and \\ larval development
}

\author{
Jorge Erick Garcia Parra' João Radünz NetoII Cátia Aline Veiverberg ${ }^{I}$ Rafael Lazzari ${ }^{I}$ \\ Giovani Taffarel Bergamin ${ }^{I}$ Fabio de Araújo Pedron ${ }^{I}$ Suzete Rossato ${ }^{\mathrm{III}}$ Fernando Jonas Sutili ${ }^{\mathrm{II}}$
}

RESUMO

O objetivo deste trabalho foi avaliar a eficiência da alimentação de fêmeas de jundiá com diferentes fontes lipídicas no desenvolvimento embrionário e larval. Foram utilizadas 12 fêmeas de jundiá (peso inicial de 500g), distribuídas ao acaso em três tanques-rede $\left(1 \mathrm{~m}^{3}\right)$, alimentadas durante 10 semanas. Foram utilizados três dietas contendo como fontes lipídicas: banha suína (BS), óleo de girassol (OG), óleo de canola (OC). No momento da eclosão, foram coletadas nas incubadoras amostras de dez (10) larvas. Uma amostra de pós-larvas foi coletada às 12, 24, 36 e 48 horas pós-eclosão para medição. Mais três amostras de pós-larvas de cada incubadora foram capturadas e criadas durante 14 dias (30 larvas $\left.L^{-1}\right)$. O desempenho das fêmeas e o desenvolvimento larval não foram afetados pelas fontes lipídicas testadas. Conclui-se que a banha suína é tão eficiente quanto óleo de girassol e canola como fontes lipídicas para fêmeas reprodutoras de jundiá e proporcionam bom desenvolvimento embrionário e larval.

Palavras-chave: banha suína, nutrição de reprodutores, óleo de canola, Rhamdia quelen.

\section{ABSTRACT}

The aim of this study was to evaluate the efficiency of feeding female South America catfish Rhamdia quelen with different lipids sources and their influence in embryo and larval stage. Twelve (12) female catfishes initial weight of $500 \mathrm{~g}$, distributed randomly among three (3) net-tanks and fed for ten (10) weeks were used. The female fishes were fed with three (3) different types of experimental diet containing lipid sources: Swine fat (BS), sunflower oil (OG) canola oil (OC). At hatch time, 10 larvae were collected from each net tank. One post larvae sample was collected at 12, 24, 36, 48 hours after hatch to verify measurement. Three samples were captured and raised in reuse water system during fourteen days (30 larvae $\left.L^{-1}\right)$. The female reproductive performance and the larval development were not affected by the lipid sources tested. The data revealed that swine fat is as good as sunflower and canola oil as lipid sources for reproductive female catfishes and that they can provide excellent embryo and larval development.

Key words: swine fat, broodstock nutrition, canola oil, Rhamdia quelen.

\section{INTRODUÇÃO}

O jundiá (Rhamdia quelen) é um bagre nativo da América Latina, habita lagos e rios, sendo muito apreciado para consumo nos países deste continente (SALHI et al., 2004). A reprodução desta espécie é anual, a desova é assincrônica, ou seja, os óvulos são liberados em várias ocasiões do período reprodutivo, e pode ser induzida pela aplicação de hormônios. A eclosão dos ovos ocorre em torno de 27 a 36h após a fertilização, e o desenvolvimento larval completa-se em 48h (abertura da boca) quando a larva possui $5 \mathrm{~mm}$ (SILVA et al., 2004) .

A reprodução em peixes, como em outros vertebrados, é afetada por fatores ambientais, sociais e nutricionais (NAVAS et al., 1998). O desenvolvimento gonadal e a fecundidade dos peixes são afetados pela nutrição dos reprodutores (BROMAGE, 1995). Por este motivo, nos últimos anos, tem sido avaliada a

IPrograma de Pós-graduação em Zootecnia, Universidade Federal de Santa Maria (UFSM), Santa Maria, RS, Brasil.

ILLaboratório de Piscicultura, Departamento de Zootecnia, 97010-120, Santa Maria, RS, Brasil. E-mail: jradunzneto@smail.ufsm.br. Autor para correspondência.

IIICurso de Zootecnia, UFSM, Santa Maria, RS, Brasil. 
importância dos nutrientes para reprodutores (FERNANDEZ-PALACIOS et al., 1997).

Informações sobre manejo alimentar de reprodutores de jundiá são inexistentes. Na prática, peixes com acúmulo de gordura, principalmente entre as vísceras, não respondem bem à desova (RADÜNZ NETO, 2004). Na criação de outras espécies de bagres, os reprodutores são usualmente alimentados com os mesmos alimentos usados para a engorda (ROBINSON \& LI, 2002). A utilização de fontes lipídicas para o crescimento do jundiá foi pesquisada (ULIANA et al., 2001; MELO et al., 2002; LOSEKANN et al., 2008), entretanto, não existem estudos sobre lipídios para reprodutores de jundiá.

Os lipídios exercem papel importante nos processos de produção de energia e como fonte de ácidos graxos essenciais (AGE) (PEZZATO, 1995). A importância dos AGE no desempenho reprodutivo tem sido observada em peixes como a truta arco-íris (Oncorhynchus mykiss) (WATANABE et al., 1984) e Sparus aurata (FERNANDEZ-PALACIOS et al., 1995; 1997), em que foi verificada que a qualidade do ovo e o desenvolvimento da larva são influenciados pela composição de AGE da dieta. Reprodutores de Dicentrarchus labrax, alimentados com restrição de lipídios na dieta, apresentam redução da fecundidade e baixa qualidade do ovo (CERDÁ et al., 1994). BALLESTRAZZI et al. (2003) verificaram que a inclusão de óleo de coco em rações para truta arco-íris influencia positivamente no número total e no peso de ovos.

Uma variedade de lipídios de origem vegetal ou animal é utilizada como ingrediente em dietas para peixes. As gorduras de animais terrestres são muito utilizadas em rações para organismos aquáticos, pois apresentam preços mais acessíveis. No entanto, essas fontes lipídicas são deficientes em ácidos graxos essenciais e, portanto, requerem uma associação com outras fontes que forneçam estes ácidos graxos (RIBEIRO et al., 2007).

O óleo de girassol é uma fonte de lipídios de origem vegetal constituída principalmente por ácidos graxos insaturados da série n-6, como ácido linoléico, porém, não contém na sua composição AGI da série $n$ 3 (NRC, 1993). O óleo de canola é fonte de lipídios de origem vegetal utilizada com muita freqüência na alimentação de peixes, estando constituída principalmente por ácido linolênico e ácido linoléico (NRC, 1993). O óleo de canola pode substituir o óleo de peixe sem afetar o desempenho reprodutivo do salmão do Atlântico (Salmo salar) (RENNIE et al., 2005).

Assim, este trabalho tem por objetivo avaliar diferentes fontes lipídicas na alimentação de fêmeas de jundiá e seu efeito sobre o desempenho embrionário e larval.

\section{MATERIAL E MÉTODOS}

O trabalho foi desenvolvido no Laboratório de Piscicultura da Universidade Federal de Santa Maria (UFSM), nos meses de julho a outubro de 2006. Foi dividido em três fases: fase I: alimentação dos reprodutores; fase II: reprodução induzida e incubação de ovos e larvas até 48 horas após a eclosão; fase III: larvicultura até os 14 dias de idade.

Para a fase I, foi utilizado um viveiro de terra $\left(900 \mathrm{~m}^{2}\right)$, com sistemas de abastecimento e drenagem de água. Neste tanque foram colocados três tanquesrede $\left(1,0 \mathrm{~m}^{3}\right)$ para as fêmeas e um tanque-rede $\left(4,0 \mathrm{~m}^{3}\right)$ para manutenção dos machos. Foram utilizadas 15 fêmeas de jundiá (peso aproximado de $500 \mathrm{~g}$ ), que receberam as dietas experimentais durante dez semanas.

Foram avaliadas três dietas contendo diferentes fontes lipídicas: banha suína (BS); óleo de girassol (OG) e óleo de canola (OC) (Tabela 1). Os ingredientes secos foram homogeneizados em amassadeira elétrica, após foi feita a adição da fonte lipídica. A banha suína foi previamente aquecida em banho-maria $\left(50^{\circ} \mathrm{C}\right)$ antes de adicionada aos ingredientes. A fim de permitir a peletização em máquina de moer carne, foi adicionada água a temperatura ambiente (50\% do peso seco dos ingredientes). A secagem foi feita em estufa $\left(50^{\circ} \mathrm{C}, 48 \mathrm{~h}\right)$.

Cada tanque-rede recebeu um dos tratamentos ( $2 \%$ do peso vivo ao dia, alimentação única fornecida às 17 horas). A ração era depositada em um comedouro (bandeja) e na alimentação seguinte, o mesmo era removido, limpo e recolocado com o alimento do dia.

Durante a Fase I, foram realizadas três biometrias (1aㅗ $5^{\underline{a} \text { e }} 10^{\underline{a}}$ semanas experimentais) para acompanhamento do desenvolvimento das fêmeas e ajuste o fornecimento de ração. Após as dez semanas de alimentação, quatro fêmeas de cada tratamento foram selecionadas de acordo com o estado reprodutivo ventre arredondado e macio e abertura urogenital levemente inchada e avermelhada (SILVA et al., 2004). Também foram selecionados 12 machos que liberassem sêmen com facilidade após leve pressão abdominal.

Para a fase II, os reprodutores foram agrupados em casais e acondicionados em um sistema com 12 incubadoras em fibra de vidro (tipo funil) de 60L, onde ocorreram a fecundação, a eclosão e o desenvolvimento larval. Na indução da desova, foi usado extrato hipofisário de carpa (4mg de hipófise $\mathrm{kg}^{-1}$ de fêmea e $2 \mathrm{mg} \mathrm{kg}^{-1}$ para cada macho, em dose única, diluído em $0,5 \mathrm{~mL}$ de soro fisiológico) aplicado na cavidade abdominal, junto à base da nadadeira peitoral (SILVA et al., 2004). 
Tabela 1 - Composição das dietas experimentais para fêmeas de jundiá (\%)*.

\begin{tabular}{|c|c|c|c|}
\hline \multirow{2}{*}{ Ingredientes } & \multicolumn{3}{|c|}{--------------------------------------- ${ }^{6}$ Dietas------------------------------------- } \\
\hline & BS & OG & OC \\
\hline Farinha de carne e ossos & 36 & 36 & 36 \\
\hline Farelo de soja & 35 & 35 & 35 \\
\hline Farelo de trigo & 16 & 16 & 16 \\
\hline Milho triturado & 4,98 & 4,98 & 4,98 \\
\hline Banha suína & 5 & - & - \\
\hline Óleo de girassol & - & 5 & - \\
\hline Óleo de canola & - & - & 5 \\
\hline Fosfato bicálcico & 1 & 1 & 1 \\
\hline Sal & 1 & 1 & 1 \\
\hline Mistura vitamínica e mineral $^{1}$ & 1 & 1 & 1 \\
\hline \multirow[t]{2}{*}{ Antioxidante $^{2}$} & 0,02 & 0,02 & 0,02 \\
\hline & \multicolumn{3}{|c|}{ Composição centesimal (\%) } \\
\hline Proteína bruta ${ }^{3}$ & 38,0 & 38,0 & 38,0 \\
\hline Energia digestível $^{4}\left(\mathrm{Kcal} \mathrm{kg}^{-1}\right)$ & 3336 & 3303 & 3314 \\
\hline Matéria mineral $^{5}$ & 14,7 & 14,6 & 14,7 \\
\hline Extrato etéreo $^{5}$ & 10,0 & 10,0 & 10,6 \\
\hline $\mathrm{ENN}^{5}$ & 27,5 & 27,3 & 27,1 \\
\hline Fibra bruta $^{5}$ & 4,3 & 4,2 & 4,2 \\
\hline Umidade $^{5}$ & 5,5 & 5,9 & 5,4 \\
\hline
\end{tabular}

*Dietas ajustadas ao experimento de acordo com LAZZARI et al. (2006).

${ }^{1}$ Composição da mistura vitamínica e mineral (por kg de produto) Ac. Fólico 400mg, Ác. Nicotínico 14000mg, Ác. Pantotênico: 8000mg, Cobalto: 1500mg, Cobre: 15000mg, Colina: 1500mg, Ferro: 50000mg, Iodo: 700mg, Manganês: 23000mg, Selênio: 250mg, Vit.A: 6000000UI, Vit.B1: 1400mg, Vit.B2: 3375mg, Vit. B6: 4830mg, Vit. B12: 5000mcg, Vit. C: 25000mg, Vit. D3: 530000 UI, Vit. E: 22500mg, Vit. K3: 5000mg, Zinco: 40000mg.

${ }^{2}$ Composição do antioxidante: Etoxiquina 32\%, Propil-galato 18\%, Veículo (talco) 50\%.

${ }^{3} \mathrm{~PB}$ Calculada em base à análise centesimal dos ingredientes.

${ }^{4} \mathrm{ED}=($ Energia digestível calculada): $[(\mathrm{PBx} 5,64 \mathrm{x0}, 84)+($ Eex9,44x0,9)+(ENNx4,11x0,60)]/100 (ROBINSON \& LI, 2002).

${ }^{5}$ Valores analisados (AOAC, 1999).

${ }^{6}$ Tratamentos: BS: Banha suína; OG: Óleo de Girassol; OC: Óleo de Canola.

Para verificar o desenvolvimento das larvas nas incubadoras, foram coletadas amostras de dez larvas no momento da eclosão (hora 0) e às 12, 24, 36 e 48 horas após a eclosão. As amostras foram fixadas em formol neutro a 4\% (EIRAS et al., 2000) para serem observadas, microfotografadas e medidas em estereoscópio-microscópio Leica M2125. Para a análise morfométrica das imagens, foi utilizado um analisador de imagens acoplado ao programa Somnium 1.0 SMN.

Para a Fase III, após a absorção do saco vitelino (48 horas depois da eclosão), foram coletadas três amostras de 160 larvas de cada incubadora e estocadas em unidades de criação (30 larvas $\mathrm{L}^{-1}$ ) de um sistema de recirculação de água. A dieta para alimentação das larvas (100-400 $\mu)$ foi preparada com os seguintes ingredientes: fígado bovino, $30 \%$ (33\%MS); levedura de cana, 57\%; lecitina de soja, $2 \%$; farelo de arroz desengordurado, 8\%; mistura vitamínica e mineral, 3\%, é ofertada seis veses/dia.

No momento da estocagem das larvas no sistema de criação, dez larvas do mesmo lote foram retiradas para amostragem inicial. Aos sete e 14 dias de criação, foi realizada a contagem das larvas das unidades experimentais para avaliação da sobrevivência e dez animais de cada repetição foram coletadas para biometria. Em todas as coletas, as larvas foram fixadas em formol neutro (4\%) para posterior medição da área total da larva (ATL, $\mathrm{mm}^{2}$ ). A taxa de crescimento específico (TCE, \% $\mathrm{dia}^{-1}$ ) foi calculada pela fórmula: $(((\ln$ Peso final $)$ - (ln Peso inicial $)) /($ dias de experimento)*100. Também foi avaliado o produto peso x sobrevivência (PxS) de cada unidade de criação. Os dados foram submetidos a teste de normalidade e após análise de variância. As médias, quando significativas, foram comparadas pelo teste de Tukey $(\mathrm{P}<0,05)$. Para realização das análises foi utilizado o software "SAS" (1997).

\section{RESULTADOS}

Na Fase I, após o período de alimentação (10 semanas), não foi observada diferença significativa ( $\mathrm{P}>0,05)$ no desempenho das fêmeas (Tabela 2). 
Tabela 2 - Desempenho de fêmeas de jundiá após 10 semanas de alimentação.

\begin{tabular}{llll}
\hline & & & \\
Variáveis & \multicolumn{1}{c}{ BS } & OG & OC \\
& & \multicolumn{1}{c}{ Inicial } & \\
\hline & & $464,5 \pm 28,7$ & \\
Peso $(\mathrm{g})$ & $466,5 \pm 16,9$ & $35,2 \pm 0,1$ & $498,2 \pm 29,5$ \\
CT $(\mathrm{cm})$ & $34,2 \pm 0,4$ & $29,5 \pm 0,2$ & $35,7 \pm 0,6$ \\
CP $(\mathrm{cm})$ & $29 \pm 0,5$ & $6,1 \pm 0,1$ & $30,5 \pm 0,6$ \\
AD $(\mathrm{cm})$ & $6,2 \pm 0,1$ & $1,0 \pm 0,07$ & $6,3 \pm 0,2$ \\
FC & $1,1 \pm 0,04$ & $2.318 \pm 114,8$ & $1,0 \pm 0,01$ \\
DE $\left(\mathrm{g} \mathrm{m}^{-3}\right)$ & $2.330 \pm 67,6$ & 70 dias & $2.468 \pm 118,0$ \\
& & $544,2 \pm 17,9$ & \\
Peso $(\mathrm{g})$ & $548,5 \pm 45,7$ & $35,2 \pm 0,3$ & $621,7 \pm 48,1$ \\
CT $(\mathrm{cm})$ & $34,7 \pm 0,5$ & $30 \pm 0,2$ & $35,9 \pm 0,8$ \\
CP $(\mathrm{cm})$ & $29,6 \pm 0,4$ & $6,0 \pm 0,2$ & $30,5 \pm 0,8$ \\
AD $(\mathrm{cm})$ & $6,0 \pm 0,3$ & $1,2 \pm 0,05$ & $6,7 \pm 0,3$ \\
FC & $1,3 \pm 0,07$ & $2.634 \pm 71,8$ & $1,3 \pm 0,09$ \\
DE $\left(\mathrm{g} \mathrm{m}^{-3}\right)$ & $2.660,5 \pm 137,2$ & $79,7 \pm 4,7$ & $2.956 \pm 192,7$ \\
GP $(\mathrm{g})$ & $82 \pm 29,7$ & & $123,5 \pm 27,5$ \\
\hline
\end{tabular}

Valores expressos em média \pm erro padrão.

Médias seguidas de letras diferentes, na linha, diferem estatisticamente entre si $(\mathrm{P}<0,05)$ pelo teste de Tukey.

Variáveis: CT: comprimento total; CP: comprimento padrão; AD: altura dorsal; FC: fator de condição; DE: densidade de estocagem; GP: ganho em peso.

Tratamentos: BS: Banha suína; OG: Óleo de Girassol; OC: Óleo de Canola.

Na Fase II foi observado que o comprimento total (CT) das larvas, entre zero e três horas após a eclosão, teve melhor desempenho (3,66mm) nos peixes provenientes das fêmeas alimentadas com óleo de girassol (OG) (Figura 1). Nos demais períodos de avaliação (12, 24, 36 e 48 horas), seguiu-se a mesma tendência, em que as larvas oriundas das fêmeas alimentadas com banha suína apresentaram menor CT $(\mathrm{P}<0,05)$.

Para a variável área total da larva (ATL), o desenvolvimento foi maior no tratamento OG $\left(3,98 \mathrm{~mm}^{2}\right)$ às 36 horas. Entretanto, às 48 horas não ocorreu diferença significativa $(\mathrm{P}>0,05)$ entre os tratamentos (Figura 1). Não foram verificadas diferenças no diâmetro do saco vitelino (DSV) das larvas. A área do saco vitelino (ASV) foi maior nas larvas provenientes das fêmeas alimentadas com óleo de canola, após 48 horas da eclosão.

Na Fase III, a sobrevivência das pós-larvas (peixes que já absorveram o vitelo) até $07^{\circ}$ dia foi melhor nos tratamentos BS e OG em relação ao tratamento OC. Para o peso, CT, CP, ATL, e peso x sobrevivência (PxS) não houve diferença entre os tratamentos. Aos 14 dias, foram observadas maiores valores de comprimento total e padrão nas pós-larvas oriundas das fêmeas alimentadas com os óleos de canola e girassol. A sobrevivência foi maior nos pós-larvas do tratamento BS em relação ao tratamento OC, porém não diferindo de OG. As outras variáveis (peso, ATL e PxS) não diferiram significativamente $(\mathrm{P}>0,05)$ entre os tratamentos testados (Tabela 3).

\section{DISCUSSÃO}

No presente trabalho não verificou-se diferença entre os pesos das fêmeas estudadas. Estudos desenvolvidos por RENNIE et al. (2005), utilizando óleo de peixe e de colza (10,5\% de inclusão de cada um) em salmão do Atlântico (Salmo salar) não mostraram diferença no peso das fêmeas. Para fêmeas de truta arco-íris, a inclusão de óleo de peixe, óleo de fígado de bacalhau ou óleo de coco em níveis crescentes não afetam o seu crescimento (BALLESTRAZZI et al., 2003).

A diminuição do DSV e da ASV é esperada, pois a larva de jundiá está crescendo e em 48 horas praticamente absorve todo seu saco vitelino. Pesquisas desenvolvidas verificando a absorção de lipídios nos primeiros dias da larva demonstram um rápido decréscimo deste nutriente e também das reservas vitelínicas (KOVEN et al., 1989; RAINUZZO et al., 1994). Após a absorção do saco vitelino, as primeiras formas predominantes de reserva de lipídios nos tecidos são os triglicerídeos e posteriormente os fosfolipídios (SARGENT et al., 1989). 


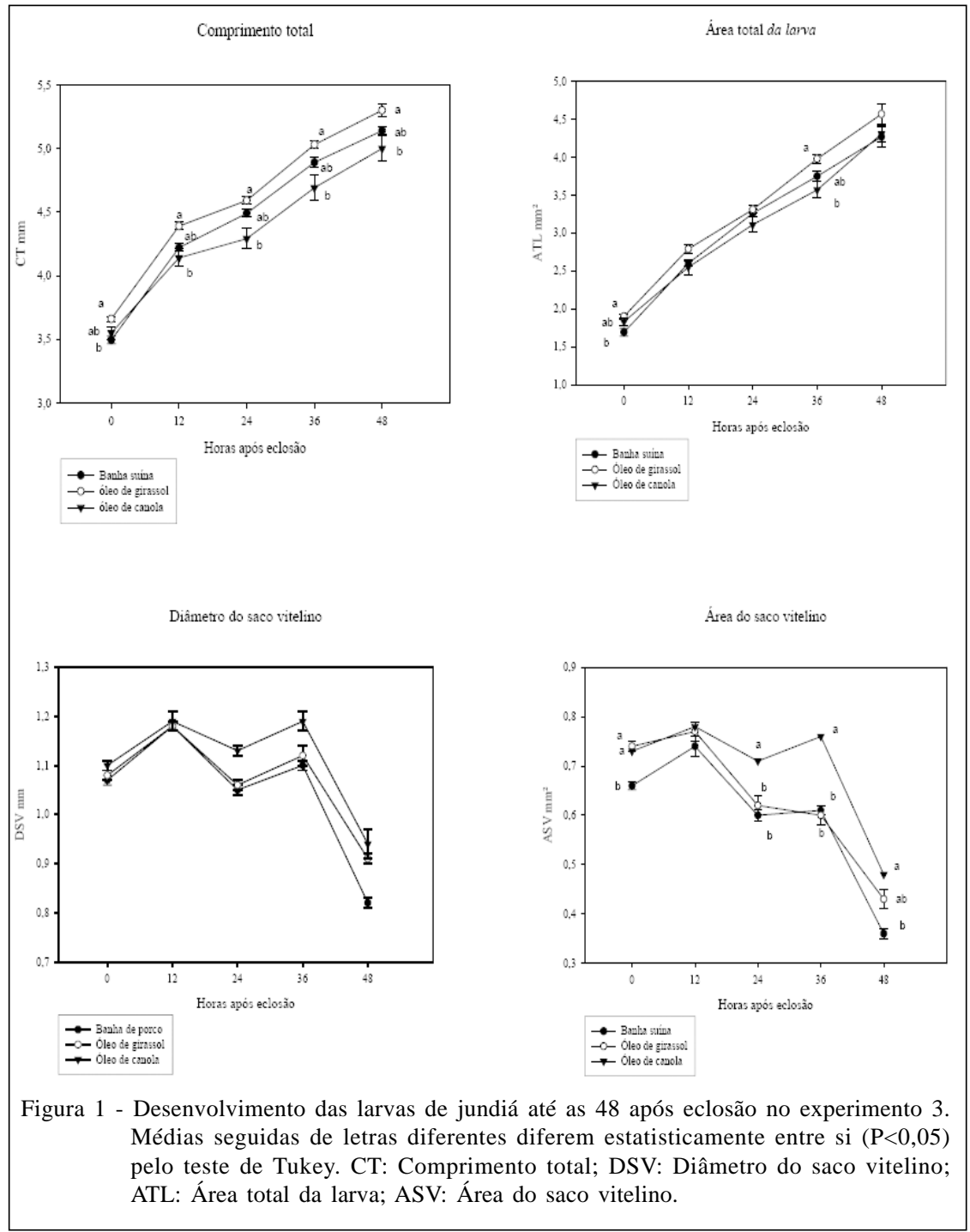

Os resultados obtidos neste estudo demonstram que as fêmeas alimentadas com uma fonte de ácidos graxos saturados (banha suína) na dieta proporcionam um menor desenvolvimento das larvas até as 48 horas após eclosão. A banha suína é uma fonte de lipídios de origem animal constituída principalmente por ácidos graxos saturados, além de ácidos graxos insaturados (AGI) das séries n-3 e n-6, em menor quantidade (NRC, 1993).

O perfil de ácidos graxos das gônadas de fêmeas de jundiá coletadas em ambiente natural apresentam certa estabilidade, sendo encontrados principalmente C16:0, C18:1n9, C20:4n6 e C22:6n3 (VARGAS \& BESSONART, 2007). Estudos neste sentido são importantes para definir-se uma dieta com quantidade e qualidade de lipídios adequados para fêmeas de jundiá, principalmente em cativeiro, em que a importância e composição do alimento natural são diferenciadas.

O efeito dos ácidos graxos essenciais, principalmente os da série n-3, atuam positivamente na desova, na qualidade do ovo e no desenvolvimento embrionário (HAREL et al. 1992). Dessa forma, em futuros estudos sobre a nutrição de fêmeas de jundiá, deverão ser consideradas não somente o tipo, mas sim a qualidade das fontes lipídicas empregadas.

É necessário considerar também que o excesso de $n-3$ nas dietas de reprodutores de "gilthead sea bream" (Sparus aurata) afeta negativamente a reprodução, provocando hipertrofia do saco vitelino das larvas e, em conseqüência, uma redução de $10 \%$ na sobrevivência até o $3^{\text {o }}$ dia de incubação (FERNANDEZ-PALÁCIOS et al., 1995). 
Tabela 3 - Desempenho das larvas de jundiá após 7 e 14 dias de alimentação na Fase III.

\begin{tabular}{|c|c|c|c|}
\hline \multirow{2}{*}{ Variáveis } & \multicolumn{3}{|c|}{-------------Dietas------------- } \\
\hline & BS & OG & OC \\
\hline & & Inicial & \\
\hline Peso (mg) & $1,4 \pm 0,1$ & $1,4 \pm 0,1$ & $1,4 \pm 0,5$ \\
\hline CT (mm) & $5,7 \pm 0,04$ & $5,7 \pm 0,06$ & $5,7 \pm 0,1$ \\
\hline $\mathrm{CP}(\mathrm{mm})$ & $4,7 \pm 0,07$ & $4,8 \pm 0,07$ & $4,8 \pm 0,1$ \\
\hline \multirow[t]{2}{*}{$\operatorname{ATL}\left(\mathrm{mm}^{2}\right)$} & $5,5 \pm 0,04$ & $5,6 \pm 0,3$ & $5,3 \pm 0,2$ \\
\hline & & 7 dias & \\
\hline Peso (mg) & $2,3 \pm 0,2$ & $2,4 \pm 0,1$ & $2,3 \pm 0,1$ \\
\hline CT (mm) & $7,1 \pm 0,7$ & $7,2 \pm 0,04$ & $7,1 \pm 0,1$ \\
\hline $\mathrm{CP}(\mathrm{mm})$ & $6,2 \pm 0,06$ & $6,3 \pm 0,03$ & $6,3 \pm 0,08$ \\
\hline $\operatorname{ATL}\left(\mathrm{mm}^{2}\right)$ & $9,4 \pm 0,2$ & $8,8 \pm 0,2$ & $8,9 \pm 0,2$ \\
\hline Sobrevivência (\%) & $95,9^{\mathrm{a}} \pm 1,2$ & $96,2^{\mathrm{a}} \pm 1,4$ & $89,9^{\mathrm{b}} \pm 2,0$ \\
\hline \multirow[t]{2}{*}{ PxS } & $2,2 \pm 0,2$ & $2,3 \pm 0,1$ & $2,1 \pm 0,1$ \\
\hline & & 14 dias & \\
\hline Peso (mg) & $11,8 \pm 0,3$ & $11,6 \pm 0,6$ & $13,6 \pm 0,9$ \\
\hline $\mathrm{CT}(\mathrm{mm})$ & $9,8^{\mathrm{b}} \pm 0,1$ & $10,5^{\mathrm{ab}} \pm 0,9$ & $10,9^{\mathrm{a}} \pm 0,2$ \\
\hline $\mathrm{CP}(\mathrm{mm})$ & $8,2^{\mathrm{b}} \pm 0,09$ & $8,4^{\mathrm{ab}} \pm 0,08$ & $8,8^{\mathrm{a}} \pm 0,1$ \\
\hline ATL $\left(\mathrm{mm}^{2}\right)$ & $21,9 \pm 3,7$ & $20,3 \pm 3,9$ & $22,9 \pm 7,5$ \\
\hline Sobrevivência (\%) & $79,8^{\mathrm{a}} \pm 0,6$ & $67,6^{\mathrm{ab}} \pm 0,7$ & $60,3^{\mathrm{b}} \pm 1,1$ \\
\hline PxS & $9,6 \pm 0,6$ & $7,9 \pm 0,7$ & $8,7 \pm 1,5$ \\
\hline TCE (\%/dia) & $15,2 \pm 0,2$ & $14,9 \pm 0,3$ & $16,1 \pm 0,5$ \\
\hline
\end{tabular}

Valores expressos em média \pm erro padrão.

Médias seguidas de letras diferentes, na linha, diferem estatisticamente entre si $(\mathrm{P}<0,05)$ pelo teste de Tukey.

CT: comprimento total; $\mathrm{CP}$ : comprimento padrão; ATL: área total da larva; PxS: produto peso $\mathrm{x}$ sobrevivência; TCE: taxa de crescimento específico.

Tratamentos: BS: Banha suína; OG: Óleo de Girassol; OC: Óleo de Canola.

\section{CONCLUSÃO}

As fontes lipídicas estudadas mostram a mesma eficiência na nutrição de fêmeas de jundiá, proporcionando bom desenvolvimento embrionário e larval.

\section{AGRADECIMENTOS}

Os autores agradecem à professora Francesca Werner Ferreira e ao Núcleo de Análise de Imagens Biológicas (NAIMB) - Laboratório de Ictiopatologia, do Departamento de Biologia e Química da Universidade Regional do Noroeste do Rio Grande do Sul - UNIJUI, pela realização das análises morfométricas; às empresas Vitagri Nutrição Animal, Zillo Lorenzetti e Cooperativa Tritícola Santiaguense, pelo fornecimento de ingredientes para elaboração das dietas; e ao SEAP/MCT/Fundo setorial Agronegócio/Fundo CT Hidro/ FINEP (Ação transversal 3602/05), pelo auxílio financeiro.

\section{REFERÊNCIAS}

AOAC (Association of Official Analytical Chemists). Official Methods of analysis of AOAC. 16.ed. Washington, DC: Patricia Cunniff, 1999. 1141p.

BALLESTRAZZI, R. et al. The effect of dietary coconut oil on reproductive traits and egg fatty acid composition in rainbow trout (Oncorhynchus mykiss). Aquaculture International, v.11, p.289-299, 2003.

BROMAGE, N.R. Broodstock management and seed quality general considerations. In: BROMAGE, N.; ROBERTS, R. (Eds). Broodstock management and egg and larval quality. Cambrige: Cambrige University, 1995. p.1-24.

CERDÁ, J. et al. Influence of nutritional composition of diet on sea bass, Dicentrarchus labrax L., reprodutive performance and egg and larval quality. Aquaculture, v.128, p.345-361, 1994.

EIRAS, C. et al. Métodos de estudo e técnicas laboratoriais em parasitologia de peixes. Maringá: EDUEM. 2000. 171p.

FERNANDEZ-PALACIOS, H. Effect of n-3 HUFA level in broodstock diets on egg quality of giltead sea bream (Sparus aurata). Aquaculture, v.132, p.325-337, 1995.

FERNANDEZ-PALACIOS, H. et al. The effect of dietary protein and lipid from squid and fish meals on egg quality of broodstock for gilthead seabream (Sparus aurata). Aquaculture, v.148, p.233-246, 1997.

HAREL, M. et al. The kineticks of nutrient incorporation in to body tissues of gilthead seabream $\boldsymbol{S}$. aurata females and subsequent effects on egg composition and egg quality. Aquaculture, v.44, p.121-127, 1992.

KOVEN, W.M. et al. Lipid and $(\mathrm{n}-3)$ requeriment of Sparus aurata larvae during starvation and feeding. Aquaculture, v.79, p.185-189, 1989.

LAZZARI, R. et al. Diferentes fontes protéicas para alimentação do jundiá (Rhamdia quelen). Ciência Rural, v.36, n.1, p.240246, 2006.

LOSEKANN, M.E. et al. Alimentação do jundiá com dietas contendo óleos de arroz, canola ou soja. Ciência Rural, v.38, n.1, p.225-230, 2008.

MELO, J.F.B. et al. Desenvolvimento e composição corporal de alevinos de jundiá (Rhamdia quelen) alimentados com dietas contendo diferentes fontes de lipídios. Ciência Rural, v.32, n.2, p.323-327, 2002.

NAVAS, J.M. et al. Effect of dietary lipid composition on vitellogenin, $17 ß$ - estradiol and gonadotropin plasma levels and spawning performance in captive sea bass (Dicentrarchus Iabrax L). Aquaculture, v.165, p.65-79, 1998.

NRC (National Research Council). Fish nutrition requirements. National Academy, 1993. 114p.

PEZZATO, L.E. Alimentos convencionais e não convencionais disponíveis para a indústria de nutrição de peixes no Brasil. In: SIMPÓSIO INTERNACIONAL SOBRE NUTRIÇÃO DE

Ciência Rural, v.38, n.7, out, 2008. 
PEIXES E CRUSTÁCEOS, 1995, Campos do Jordão. Anais... Campos do Jordão: CBNA, 1995. p.35-52.

RADÜNZ NETO, J. Manejo alimentar - Nutrição. In: BALDISSEROTO, B.; RADÜNZ NETO, J. Criação de jundiá. Santa Maria: UFSM, 2004. p.143-160.

RAINUZZO, J.R. et al. The significance of lipids at early stages of marine fish: a review. Aquaculture, v.155, p.103115, 1997.

RENNIE, S. et al. Long term partial replacement of dietary fish oil with rapessed oil; effects on egg quality of Atlantic salmon Salmo salar. Aquaculture, v.248, p.135-146, 2005

RIBEIRO, P.A.P. et al. Nutrição lipídica para peixes. Revista eletrônica Nutritime, v.4, n.2, p.426-445. 2007. Disponível em http://www.nutritime.com.br.

ROBINSON, E.H.; LI, M.H. Channel catfish, Ictalurus punctatus. In: WEBSTER, C D.; LIM, C.E. (Eds.). Nutrient requirements and feeding of finfish for aquaculture. London, NY: CABI, 2002. p.293-318.

SALHI, M. et al. Growth feed utilization and body composition of black catfish, Rhamdia quelen, fry fed diets containing differents protein and energy levels. Aquaculture, v.231, p.435-444, 2004.

SARGENT, J.L. et al. The lipids. In: HALVER. J.E. (Ed.). Fish nutrition. 2.ed. New York: Academy, 1989. 798p.

SAS. Statistical Analysis System. User's guide. Version 6.08, SAS INSTITUTE INC. 4.ed. North Caroline, 1997. 846p.

SILVA, L.V.F. et al. Reprodução. In: BALDISSEROTO, B.; RADÜNZ NETO, J. Criação de jundiá. Santa Maria: UFSM, 2004. p.95-106.

ULIANA, O. et al. Diferentes fontes de lipídios testadas na criação de larvas de jundiá (Rhamdia quelen), Pisces, Pimelodidae. Ciência Rural, v.31, n.1, p.129-133, 2001.

VARGAS, R.J; BESSONART, M. Análisis preliminaries de la composición lipídica de las gónadas de bagre negro, Rhamdia quelen (Siluriformes; Quoy y Gaimard, 1824) de dos poblaciones en diferentes estaciones del año. Boletim do Instituto de Pesca, v.33, n.01, p.93-98, 2007.

WATANABE, T. et al. Effect of low protein-high calory or essential fatty acid deficiency diet on reprodution of Rainbow trout. Bulletin of the Japanese Scientific Fisheries, v.50, p.1207-1215, 1984 